\title{
Opposite Change of In Vivo Dopamine Release in the Rat Nucleus Accumbens and Striatum That Follows Electrical Stimulation of Dorsal Raphe Nucleus: Role of 5- $\mathrm{HT}_{3}$ Receptors
}

\author{
Philippe De Deurwaerdère, ${ }^{1}$ Luis Stinus, ${ }^{2}$ and Umberto Spampinato ${ }^{1}$ \\ 1/nstitut National de la Santé et de la Recherche Médicale Unité 259 and 'Laboratoire Neuropsychobiologie des \\ Désadaptations, Unité Mixte de Recherche-Centre National de la Recherche Scientifique 5541, Université Victor Ségalen \\ Bordeaux 2, 33077 Bordeaux Cedex, France
}

In the present study we investigate, using in vivo microdialysis, the involvement of central $5-\mathrm{HT}_{3}$ receptors in the effect of dorsal raphe nucleus (DRN) electrical stimulation on dopamine (DA), 3,4-dihydroxyphenylacetic acid (DOPAC), and 5-hydroxyindole-3-acetic acid (5-HIAA) extracellular levels monitored in the nucleus accumbens and the striatum of halothane-anesthetized rats. DRN stimulation (300 $\mu \mathrm{A}, 1 \mathrm{msec}$ at $3,5,10$, and $20 \mathrm{~Hz}$ for $15 \mathrm{~min}$ ) induced a frequencydependent increase of accumbal DA release and a concomitant reduction of DA release in the ipsilateral striatum at $20 \mathrm{~Hz}$. In both structures DOPAC and 5-HIAA dialysate contents were enhanced in a frequency-dependent manner. Central serotonin (5-HT) depletion, induced by intra-raphe injections of 5,7dihydroxytryptamine neurotoxin, abolished the effect of $20 \mathrm{~Hz}$ DRN stimulation on DA, DOPAC, and 5-HIAA extracellular levels in both regions. The 5-HT synthesis inhibitor parachlorophenylalanine $(3 \times 400 \mathrm{mg} / \mathrm{kg}$, i.p., for $3 \mathrm{~d})$, although preventing the effect on DA release, failed to modify significantly the effect of $20 \mathrm{~Hz}$ DRN stimulation on DOPAC and 5-HIAA outflow in both structures. Ondansetron $(0.1$ and 1 $\mathrm{mg} / \mathrm{kg}$ ) and $(S)$-zacopride $(0.1 \mathrm{mg} / \mathrm{kg})$, two $5-\mathrm{HT}_{3}$ antagonists, significantly impaired the increase of accumbal DA release induced by $20 \mathrm{~Hz}$ DRN stimulation but did not affect either the decrease of striatal DA release or the increase in DOPAC outflow in both structures. These results indicate that an enhancement of central 5-HT transmission induced by DRN stimulation differentially affects striatal and accumbal DA release and that endogenous $5-\mathrm{HT}$, via its action on $5-\mathrm{HT}_{3}$ receptors, exerts a facilitatory control restricted to the mesoaccumbal DA pathway.

Key words: microdialysis; nucleus accumbens; striatum; dopamine release; dorsal raphe nucleus; electrical stimulation; serotonin; 5- $\mathrm{HT}_{3}$ receptors; 5,7-dihydroxytryptamine; parachlorophenylalanine; halothane-anesthetized rat
It has been known for many years that serotonergic (5-HT) neurons from the raphe nuclei innervate the nigrostriatal and mesolimbic dopaminergic (DA) systems at both somatodendritic and terminal levels (Azmitia and Segal, 1978; Wirtshafter et al., 1987; Van Bockstaele et al., 1994) and that 5-HT is able to modulate DA neuron activity in mammals (Soubrié et al., 1984). Recently, several preclinical and clinical studies have shown that 5-HT drugs could improve the therapy of neuropsychiatric disorders related to nigrostriatal or mesolimbic DA neuron dysfunctions such as Parkinson's disease or schizophrenia (Deutch et al., 1991; Meltzer and Nash, 1991; Kapur and Remington, 1996). So that the side effects induced by long-term DA treatments (i.e., neuroleptic-induced tardive dyskinesia or levodopa-induced psychosis) can be reduced, it is crucial to achieve an independent modulation of either mesolimbic or nigrostriatal DA pathways. This could be obtained via selective stimulation of the various 5-HT receptor subtypes that are distributed differentially

\footnotetext{
Received March 6, 1998; revised May 28, 1998; accepted June 1, 1998.

This work was supported by grants from Institut National de la Santé et de la Recherche Médicale and Bordeaux 2 Université. P.D.D. was a fellowship recipient from the Ministère de la Recherche et de l'Enseignement Superieur during the course of this study. We thank Dr. M. Gingrass for linguistic assistance.

Correspondence should be addressed to Professor U. Spampinato at his present address: Laboratoire de Neuropsychobiologie des Désadaptations, Université Victor Ségalen Bordeaux 2, Unité Mixte de Recherche-Centre National de la Recherche Scientifique 5541, Boîte Postale 31, 146 Rue Léo Saignat, 33076 Bordeaux Cedex, France.

Copyright (ㄷ) 1998 Society for Neuroscience $\quad 0270-6474 / 98 / 186528-11 \$ 05.00 / 0$
}

throughout the brain (Hoyer et al., 1994). In line with this idea $5-\mathrm{HT}_{3}$ receptors, which display higher density in limbic and cortical areas with respect to the nigrostriatal system (Kilpatrick et al., 1987; Barnes et al., 1990), have been claimed to be a useful target for selective modulation of mesolimbic DA system activity (Costall et al., 1987; Deutch et al., 1991). However, the experimental support to this hypothesis is not strong and often is controversial. Although behaviors related to the nigrostriatal DA system activity such as stereotypy or catalepsy appear to be insensitive to $5-\mathrm{HT}_{3}$ antagonists (Costall et al., 1987; Hicks, 1990), behaviors resulting from the stimulation of the mesolimbic DA system such as locomotor hyperactivity, drug selfadministration, and conditioned place preference either are reduced (Costall et al., 1987; Carboni et al., 1989a; Svingos and Hitzemann, 1992; Hui et al., 1993) or are not affected (Carboni et al., 1989a; Peltier and Schenk, 1991; Cervo et al., 1996) by 5-HT receptor antagonists. Furthermore, biochemical investigations have shown that $5-\mathrm{HT}_{3}$ receptor stimulation increases DA release in the nucleus accumbens (NAC) (Jiang et al., 1990; Parsons and Justice, 1993). However, in the case of the enhancement of accumbal DA release induced by drugs of abuse, some studies have shown an involvement of $5-\mathrm{HT}_{3}$ receptors (Carboni et al., 1989b; Imperato and Angelucci, 1989; Pei et al., 1993) whereas others have not (Carboni et al., 1989b; Cervo et al., 1996). Finally, although most biochemical data have shown that $5-\mathrm{HT}_{3}$ receptors are not involved in the control of striatal DA release (Zazpe et al., 1994; Bonhomme et al., 1995), a facilitatory effect 
induced by striatal $5-\mathrm{HT}_{3}$ receptor stimulation has been reported (Blandina et al., 1989). Given the available data, it is not possible at present to conclude whether endogenous 5-HT, via central $5-\mathrm{HT}_{3}$ receptors, selectively modulates the mesoaccumbal DA pathway.

To address this question, we coupled dorsal raphe nucleus (DRN) electrical stimulation, which has been shown to be a useful tool for increasing central 5-HT transmission (Sharp et al., 1989), to in vivo microdialysis in the present study. Extracellular levels of DA, 3,4-dihydroxyphenylacetic acid (DOPAC), and 5-hydroxyindole-3-acetic acid (5-HIAA) were monitored in both the rat striatum and NAC simultaneously. To assess the involvement of endogenous $5-\mathrm{HT}$ and $5-\mathrm{HT}_{3}$ receptors in the effect of DRN stimulation, we performed experiments in rats bearing a lesion of central 5-HT system or who were administered selective $5-\mathrm{HT}_{3}$ antagonists.

\section{MATERIALS AND METHODS}

Animals. Male Sprague Dawley rats (IFFA CREDO, Lyon, France) weighing 330-360 gm were used. Animals were kept at constant room temperature $\left(21 \pm 2^{\circ} \mathrm{C}\right)$ and relative humidity $(60 \%)$ with a $12 \mathrm{hr}$ light/dark cycle (dark from 8 P.M.) and had free access to water and food. All experiments were conducted in conformity with French legislation concerning animal experimentation [number 87-848 transcribed from a European Economic Community (CEE) publication, number 86/609/CEE].

Drugs. The following compounds were used: 5,7-dihydroxytryptamine (5,7-DHT) creatinine sulfate, desmethylimipramine hydrochloride (Research Biochemicals, Natick, MA), para-chlorophenylalanine (pCPA) hydrochloride (Sigma, St. Louis, MO), ondansetron dihydrochloride (1,2,3,9,-tetrahydro-9-methyl-3[(2-methyl-1-imidazol-1-yl) methyl] ${ }^{4} \mathrm{H}$ carbazol-4-one) (Glaxo Research Group, Ware, Hertfordshire, UK), and $(S)$-zacopride hydrochloride (Delalande-Synthelabo, Bagneux, France). All other chemicals and reagents were the purest commercially available (Merck, Prolabo).

Microdialysis. Surgery and perfusion procedures were performed as previously described (Bonhomme et al., 1995), with minor modifications. Briefly, rats were anesthetized with a mixture of halothane and nitrous oxide-oxygen $(1 \% ; 2: 1 \mathrm{v} / \mathrm{v})$. After tracheotomy for artificial ventilation the animals were placed in a stereotaxic frame, and their rectal temperature was monitored and maintained at $37.3^{\circ} \mathrm{C} \pm 0.1$ with a heating pad. Two microdialysis probes, 2 and $3 \mathrm{~mm}$ long $(240 \mu \mathrm{m}$, Cuprophan, Carnegie Medicin Phymep, Paris, France) were implanted simultaneously, using a dual probe holder (CMA Phymep), in the right NAC and striatum [coordinates from interaural point: anteroposterior $(\mathrm{AP})=$ 11 , lateral $(\mathrm{L})=1.3$, ventral $(\mathrm{V})=2$ and $\mathrm{AP}=9.8, \mathrm{~L}=3.3, \mathrm{~V}=3$, respectively] according to the atlas of Paxinos and Watson (1986). Probes were perfused at a constant rate of $2 \mu \mathrm{l} / \mathrm{min}$ by means of a microperfusion pump (CMA111, Carnegie Medicin Phymep) with artificial CSF containing (in mM): $154.1 \mathrm{Cl}^{-}, 147 \mathrm{Na}^{+}, 2.7 \mathrm{~K}^{+}, 1 \mathrm{Mg}^{2+}$, and $1.2 \mathrm{Ca}^{2+}$, adjusted to $\mathrm{pH} 7.4$ with 2 sodium phosphate buffer. Dialysates $(30 \mu \mathrm{l})$ were collected on ice every $15 \mathrm{~min}$. The in vitro recoveries of the probes were $\sim 10 \%$ for DA, DOPAC, and 5-HIAA.

DRN electrical stimulation. Shortly after the implantation of dialysis probes, a concentric electrode (SNE-100, Rhodes Medical Instruments, Woodland Hills, CA) was lowered stereotaxically into the DRN (coordinates from lambda: $A P=0.9 \mathrm{~mm}, \mathrm{~L}=0.0 \mathrm{~mm}, \mathrm{~V}=-6.0 \mathrm{~mm}$ ) according to the atlas of Paxinos and Watson (1986). The electrode was connected via a current isolation unit (Digitimer 4030) to a stimulator (Isolated Stimulator type 2533), and output was monitored by an oscilloscope. DRN was stimulated electrically for $15 \mathrm{~min}$ with cathodal monophasic pulses ( $1 \mathrm{msec}$ duration) at $300 \mu \mathrm{A}$ and a pulse frequency ranging from 3 to $20 \mathrm{~Hz}$, according to the protocol described by Sharp et al. (1989).

At the end of each experiment the site of stimulation was marked by passing a $10 \mathrm{sec}$ DC anodal current of $3 \mathrm{~mA}$, and the brain was removed and fixed in a saline $(0.9 \%)$ and paraformaldehyde solution $(10 \%)$. The location of the electrode and of the microdialysis probes, shown in Figure 1 , was determined histologically on serial coronal sections $(100 \mu \mathrm{m}$ for dialysis probes and $40 \mu \mathrm{m}$ for electrode) stained with cresyl violet.

5-HT depletion by 5,7-DHT or pCPA. 5,7-DHT neurotoxin (Baumgar-
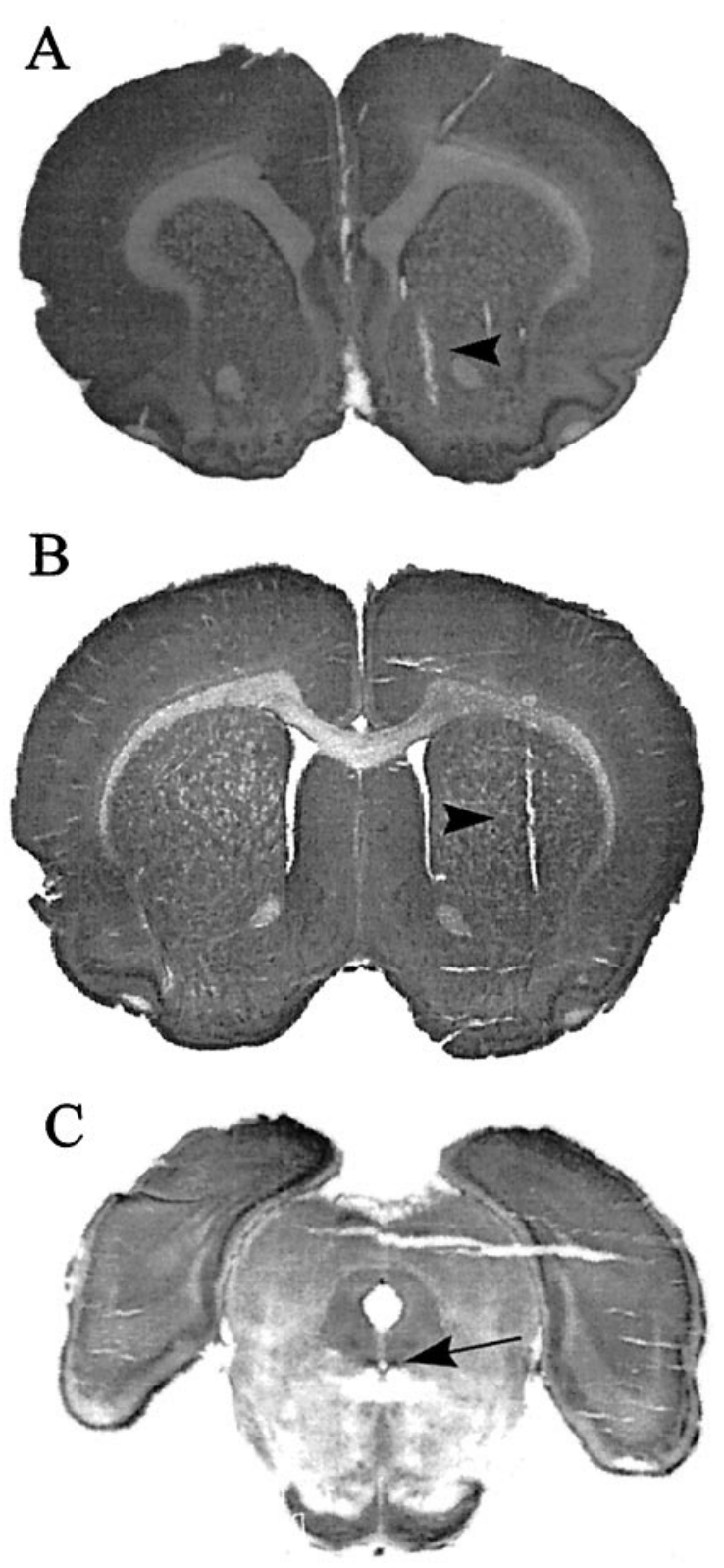

$1 \mathrm{~mm}$

Figure 1. Photomicrographs from cresyl violet-stained coronal brain sections through the nucleus accumbens (NAC) $(A)$, the striatum $(B)$, and the dorsal raphe nucleus (DRN) $(C)$, showing the tracks left by the microdialysis probes and the electrode. Two microdialysis probes were implanted simultaneously within the right NAC (2-mm-membrane long) and the right striatum (3-mm-membrane long) by stereotaxic surgery. Thereafter, a bipolar concentric electrode was lowered stereotaxically into the DRN (see Materials and Methods). Arrows indicate the tracks left by the microdialysis membrane and the tip of the electrode corresponding to the stimulation site within the DRN.

ten et al., 1973) and the tryptophan hydroxylase inhibitor pCPA (Koe and Weissmann, 1966) were used to deplete central 5-HT content. In the 5,7-DHT experiment the rats, initially weighing 260-280 gm, were anesthetized with chloral hydrate $(400 \mathrm{mg} / \mathrm{kg}$, i.p.) and immobilized in a stereotaxic apparatus. Lesion of 5-HT neurons was performed by two bilateral injections of 5,7-DHT into the DRN. Briefly, $4 \mu \mathrm{g}$ of 5,7-DHT, calculated as free base, dissolved in $2 \mu \mathrm{l}$ of $0.9 \%$ saline containing $0.1 \%$ ascorbic acid was delivered through two stainless-steel cannulae $(30 \mathrm{G})$ placed on each DRN side at a constant flow rate of $0.3 \mu \mathrm{l} / \mathrm{min}$. In this 
case the stereotaxic coordinates $(\mathrm{AP}=+0.6 /-0.4, \mathrm{~L}= \pm 0.5, \mathrm{~V}=$ $-7.7 /+3.1$, with respect to the bregma) were determined according to the atlas of Pellegrino and Cushman (1967) to avoid damage of the sinus when the two stainless steel cannulae were lowered into the DRN. Sham-operated animals (controls) received an identical volume of vehicle alone. To prevent damage to the noradrenergic system, we gave all of the animals an intraperitoneal administration of desmethylimipramine (25 mg/kg) 30-45 min before 5,7-DHT injection (Baumgarten et al., 1973). Dialysis experiments were performed 18-21 d after surgery. pCPA was administered according to the procedure described by Trent and Tepper (1991). Briefly, $400 \mathrm{mg} / \mathrm{kg} \mathrm{pCPA}$, considered as a salt, was dissolved just before use in saline ( $\mathrm{NaCl} 0.9 \%)$ and daily administered intraperitoneally in $3 \mathrm{ml} / \mathrm{kg}$ body weight 72,48 , and $24 \mathrm{hr}$ before dialysis experiments. Control rats were injected with an equal volume of vehicle only. In each animal the efficacy of 5,7-DHT and pCPA treatments to impair central 5-HT transmission was evaluated in vivo by monitoring striatal and accumbal extracellular levels of 5-HIAA, which has been shown to correlate positively with the magnitude of central 5-HT neuron depletion (Kirby et al., 1995). In addition, in a separate experiment the success and selectivity of 5,7-DHT and pCPA lesion were assessed by measuring the concentrations of noradrenaline (NA), 5-HT, and DA in different brain areas of control and treated rats.

Chromatographic analysis. All chromatographic analysis was performed as described elsewhere (Bonhomme et al., 1995; De Deurwaerdère et al., 1995). Dialysate samples were analyzed immediately by reverse-phase HPLC with electrochemical detection (HPLC-ECD). The mobile phase [containing (in $\mathrm{mm}$ ) $70 \mathrm{NaH}_{2} \mathrm{PO}_{4}, 0.1 \mathrm{Na}_{2}$-EDTA, 0.7 triethylamine, and 0.1 octylsulfonic acid plus $10 \%$ methanol, adjusted to pH 4.8 with orthophosphoric acid] was delivered at $1 \mathrm{ml} / \mathrm{min}$ flow rate (System Gold, Beckman, Paris, France) through a Hypersil column (C18, $4.6 \times 150 \mathrm{~mm}, 5 \mu \mathrm{m}$, Touzard et Matignon, Paris, France). Detection of DA, DOPAC, and 5-HIAA was performed with a coulometric detector (CoulochemII, ESA, Paris, France) coupled to a dual-electrode analytic cell (model 5014). The potential of the electrodes was set at -175 and $+175 \mathrm{mV}$. Under these conditions the sensitivity for DA was $0.5 \mathrm{pg} / 30 \mu \mathrm{l}$, with a signal-to-noise ratio of $3: 1$.

Tissue concentrations of biogenic amines (NA, 5-HT, and DA) and DA metabolites [DOPAC and homovanillic acid (HVA)] were measured by HPLC-ECD in different brain areas of control and treated rats after a $21 \mathrm{~d}$ recovery period in the case of 5,7-DHT experiments or $24 \mathrm{hr}$ after the last injection of pCPA. Rats were decapitated; brains were removed rapidly and frozen on dry ice. Frontal brain sections (from 500 to 1000 $\mu \mathrm{m}$ ) were prepared by using a cryostat, and bilateral punches of discrete regions [NAC, striatum, dorsal hippocampus, substantia nigra $(\mathrm{SN})$, and ventral tegmental area (VTA)] were made with stainless steel cannulae of 800,1200 , and $2000 \mu \mathrm{m}$ inner diameter. Punches were stored at $-80^{\circ} \mathrm{C}$ until their use in biochemical assays. One week later the tissues were homogenized in 75-200 $\mu \mathrm{l}$ of $0.1 \mathrm{~N} \mathrm{HClO}_{4}$ (depending on the tissue weight) and centrifuged at $13,000 \mathrm{rpm}$ for $30 \mathrm{~min}$ at $4^{\circ} \mathrm{C}$. Aliquots $(10-20$ $\mu \mathrm{l})$ of the supernatants were injected into the HPLC column (Chromasyl $\mathrm{C} 8,150 \times 4.6 \mathrm{~mm}, 5 \mu \mathrm{m})$ protected by a Brownlee-Newgard precolumn (RP-8, $15 \times 3.2 \mathrm{~mm}, 7 \mu \mathrm{m})$, after dilution with appropriate volumes of mobile phase. The mobile phase, delivered at $1.2 \mathrm{ml} / \mathrm{min}$ flow rate, was as follows (in $\mathrm{mM}$ ): $60 \mathrm{NaH}_{2} \mathrm{PO}_{4}, 0.1$ disodium EDTA, and 2 octane sulfonic acid plus $7 \%$ methanol, adjusted to $\mathrm{pH} 3.9$ with orthophosphoric acid and filtered through a $0.22 \mu \mathrm{m}$ Millipore filter. Detection of compounds was performed with a coulometric detector (CoulochemI, ESA) coupled to a conditioning cell (model 5100) and a dual-electrode analytic cell (model 5011). The potential of the electrodes was set at +350 and $-270 \mathrm{mV}$, whereas that of the conditioning cell was set at $+100 \mathrm{mV}$. Tissue protein content was determined by the method of Lowry et al. (1951). Results are expressed as nanogram per milligram of proteins, and each value is the mean \pm SEM.

Experimental procedure. DRN electrical stimulation and $5-\mathrm{HT}_{3}$ antagonist treatments were performed after the stabilization of DA, DOPAC, and 5-HIAA levels in the perfusates. A stable baseline, defined as three consecutive samples in which DA, DOPAC, and 5-HIAA contents varied by $<10 \%$ in both structures, generally was obtained 120-150 min after the beginning of the perfusion (stabilization period). In all experiments each rat received a single 15 min DRN electrical stimulation that was at $3,5,10$, or $20 \mathrm{~Hz}$. In control animals the electrode was lowered into DRN, but no electrical stimulation was performed (sham-stimulated group). The effect of $20 \mathrm{~Hz}$ DRN electrical stimulation also was studied in animals bearing a lesion of 5-HT system (5,7 DHT- and pCPA-treated animals) or given $5-\mathrm{HT}_{3}$ receptor antagonists. In this latter case, ondan- setron ( 0.1 and $1 \mathrm{mg} / \mathrm{kg}$ base) and $(S)$-zacopride $(0.1 \mathrm{mg} / \mathrm{kg}$ base $)$, dissolved in $0.9 \% \mathrm{NaCl}$ just before use, were administered subcutaneously in $1 \mathrm{ml} / \mathrm{kg}$ body weight $30 \mathrm{~min}$ before DRN stimulation. Both compounds were used at doses known to block selectively the central $5-\mathrm{HT}_{3}$ receptor-mediated responses in rodents (Costall et al., 1987; Svingos and Hitzemann, 1992). In particular, the dose of $0.1 \mathrm{mg} / \mathrm{kg}$ $(S)$-zacopride was chosen to avoid central $5-\mathrm{HT}_{4}$ receptor stimulation (Fontana et al., 1996).

Statistical analysis. In dialysis experiments the DA, DOPAC, and 5-HIAA content in each dialysate sample was expressed as the percentage of the average baseline level calculated from the three fractions preceding any treatment. Data correspond to the mean \pm SEM values of the percentage obtained in each experimental group. The statistical analysis of the effect of $3,5,10$, and $20 \mathrm{~Hz}$ DRN stimulation on the time courses of DA, DOPAC, and 5-HIAA extracellular levels was performed in three dialysates after the baseline was obtained by a one-way ANOVA with repeated measures, using the stimulation frequency as the main factor. When the result of ANOVA was significant $(p<0.05)$, a post hoc Dunnett's test was performed to determine statistical significance $(p<$ 0.05 ) between stimulated and control groups for each time point. The overall effect of central 5-HT depletion induced by 5,7-DHT or pCPA administration on the effect of $20 \mathrm{~Hz}$ DRN stimulation on DA, DOPAC, and 5-HIAA dialysate content was assessed by a one-way ANOVA with repeated measures, using 5,7-DHT or pCPA treatments as the main factor. When ANOVA results were significant, a post hoc two-tailed Student's $t$ test also was performed. The ability of $5-\mathrm{HT}_{3}$ antagonists to counteract the effect of $20 \mathrm{~Hz}$ DRN stimulation on extracellular levels of DA, DOPAC, and 5-HIAA was assessed by a two-way ANOVA (stimulation $\times$ antagonist) with repeated measures for the three dialysates collected during and after DRN stimulation. When significant, the post hoc Tukey's test permitted adequate multiple comparison for each time point. Finally, the effect of 5,7-DHT or pCPA treatment on 5-HT, DA, NA, and DA metabolite tissue levels, as well as on DA, DOPAC, and 5-HIAA basal dialysate content from the NAC and the striatum, was analyzed with a two-tailed Student's $t$ test. Differences between control and treated rats were considered significant if $p<0.05$.

\section{RESULTS}

\section{Basal extracellular DA, DOPAC, and 5-HIAA concentrations in dialysates from the NAC and the striatum}

All measurements were performed $150 \mathrm{~min}$ after the beginning of perfusion, when a steady state was achieved. Absolute basal levels of DA, DOPAC, and 5-HIAA in dialysate simultaneously collected from the NAC and the striatum, taken as the mean \pm SEM of the three values preceding DRN electrical stimulation, were, respectively (without adjusting for probes recovery) $6.3 \pm 0.8$, $2989 \pm 314$, and $702 \pm 59 \mathrm{pg} / 30 \mu \mathrm{l}$ in the NAC $(n=27)$ and $16.3 \pm 1.5,3104 \pm 289$, and $932 \pm 64 \mathrm{pg} / 30 \mu \mathrm{l}$ in the striatum $(n=27)$.

\section{Effect of DRN electrical stimulations on DA, DOPAC, and 5-HIAA extracellular levels in the NAC and the striatum}

Figure 2 illustrates the effect of DRN electrical stimulation on DA, DOPAC, and 5-HIAA dialysate content from the NAC and the striatum. DRN stimulation at 5,10 , and $20 \mathrm{~Hz}$, but not at 3 $\mathrm{Hz}$, induced a significant increase of DA release in the NAC $(p<$ 0.01 , Dunnett's test) $\left[F_{(4,22)}=18.3, p<0.001\right]$. The effect elicited by 5 and $10 \mathrm{~Hz}$ stimulation peaked in the first fraction (115 and $123 \%$ of basal values, respectively), whereas a sustained increase of DA release was observed after $20 \mathrm{~Hz}$ stimulation, reaching its maximum $(141 \%) 15 \mathrm{~min}$ after the offset of DRN stimulation $(p<0.01$, Dunnett's test $)$. In the striatum, DA release was decreased significantly $(-20 \%)$ only after $20 \mathrm{~Hz}$ DRN stimulation $\left[F_{(4,22)}=7.2, p<0.001\right.$ and $p<0.01$, Dunnett's test $]$. This effect was transient, and DA levels returned to control values within $30 \mathrm{~min}$ after the offset of stimulation. In contrast to DA, DOPAC extracellular levels were enhanced in a frequency- 
NAC

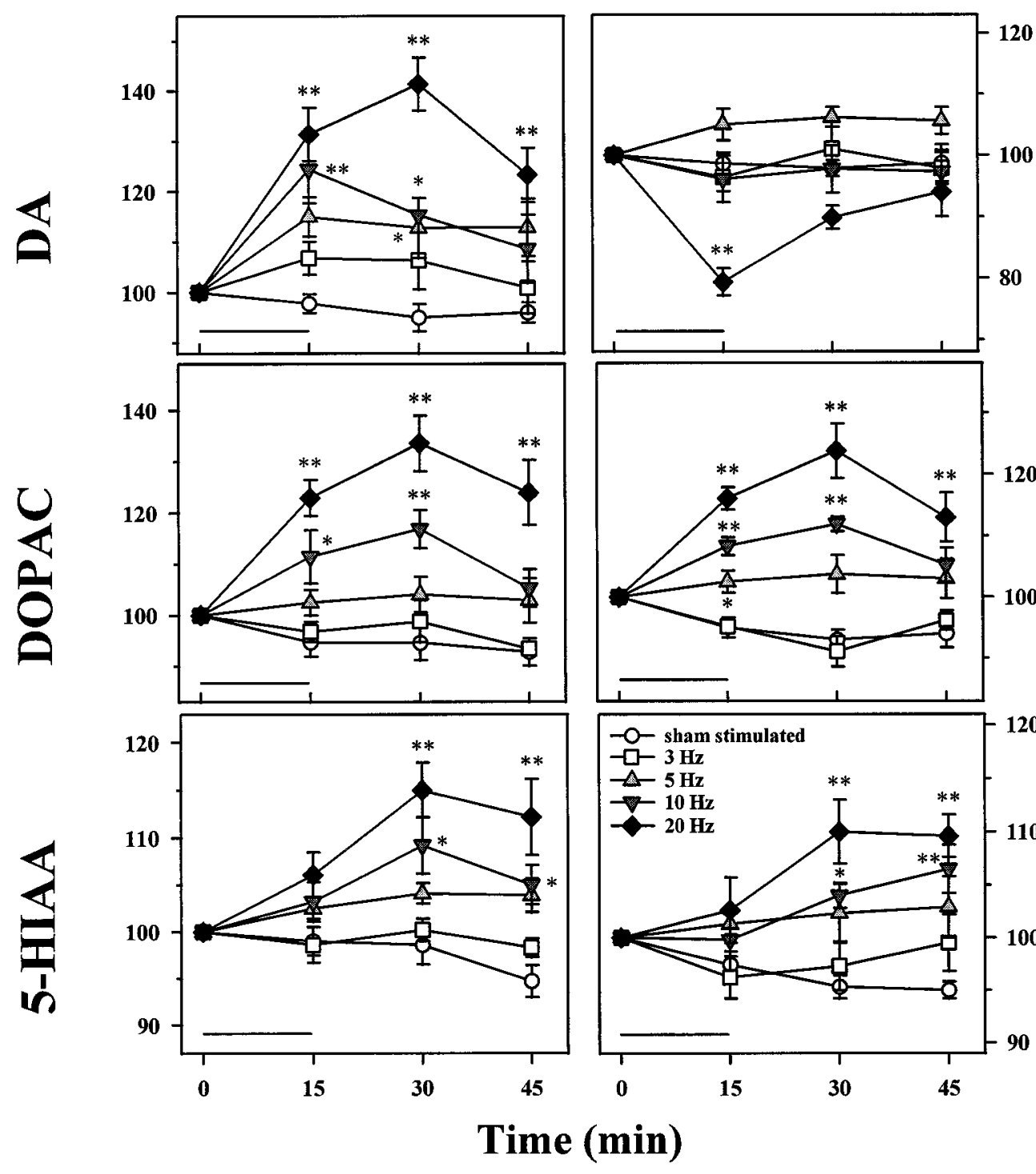

striatum

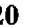

Figure 2. Time course of the effect of dorsal raphe nucleus (DRN) electrical stimulation at 3,5,10, and $20 \mathrm{~Hz}$ on DA, DOPAC, and 5-HIAA extracellular levels in the rat nucleus accumbens $(N A C)$ and striatum. Each data point represents the mean percentage \pm SEM of baseline values calculated from three samples before DRN stimulation, performed for a $15 \mathrm{~min}$ period as indicated by the horizontal bar. Each experiment was performed on five or six animals per group. ${ }^{*} p<$ 0.05 and ${ }^{* *} p<0.01$ as compared with the sham-stimulated group (unfilled circles) for each time point (Dunnett's test). dependent manner in both the NAC $\left[F_{(4,22)}=12.1, p<0.001\right]$ and the striatum $\left[F_{(4,22)}=23.5, p<0.001\right]$. The maximal increase of DOPAC outflow was observed 15 min after DRN stimulation either in the NAC (120 and $135 \%$ of basal levels at 10 and $20 \mathrm{~Hz}$, respectively) or in the striatum (112 and $121 \%$ of baseline values at 10 and $20 \mathrm{~Hz}$, respectively) ( $p<0.01$ in all cases, Dunnett's test). Finally, 10 and $20 \mathrm{~Hz}$ DRN stimulation also elicited a significant enhancement of 5-HIAA outflow in both the NAC $\left[F_{(4,22)}=7.94, p<0.001\right]$ and the striatum $\left[F_{(4,22)}=6.46, p<\right.$ $0.01]$. The effect was maximal 15 and $30 \mathrm{~min}$ after stimulation ( $p<0.05$ and $p<0.01$, Dunnett's test). No significant changes were observed after 3 and $5 \mathrm{~Hz}$ of DRN stimulation (Dunnett's test).

\section{Tissue and dialysate levels of biogenic amines and their metabolites after 5,7-DHT or pCPA treatment}

The bilateral microinjections of 5,7-DHT into the DRN resulted in a marked depletion of 5-HT content in the various brain regions that were examined. Thus, the lesion led to a drastic decrease in the levels of 5-HT in the striatum and ventral tegmental area (VTA; -97\%) and, to a lesser extent (approximately
$-95 \%)$, in the other investigated areas $(p<0.001$, Student's $t$ test; Table 1), indicating a massive degeneration of 5-HT projections from the DRN (Azmitia and Segal, 1978). The reduction of 5-HT content found in the dorsal hippocampus revealed that 5-HT neurons in the median raphe nucleus also were affected by the lesion (Azmitia and Segal, 1978). The unchanged levels of NA, DA (Table 1), and its metabolites DOPAC and HVA (data not shown) indicated that neither the noradrenergic nor the dopaminergic system was affected significantly by the lesion.

Tissue 5-HT content also was reduced dramatically by pCPA treatment in all of the brain regions examined. The decrease was maximal in the striatum, the NAC, and the dorsal hippocampus $(-95 \%)$, followed by the SN (approximately -90\%) and the VTA $(-83 \%)$. In contrast to 5,7-DHT treatment, pCPA also produced a moderate but significant reduction in the levels of catecholamines in some brain regions. Thus, a decrease of NA content was found in the dorsal hippocampus $(-57 \% ; p<0.01$, Student's $t$ test; Table 1$)$, and a reduction of DA content was observed in the NAC $(-46 \% ; p<0.01$, Student's $t$ test; Table 1$)$. In addition, DOPAC and HVA levels were lowered significantly 


\begin{tabular}{|c|c|c|c|c|}
\hline & 5,7-DHT & & pCPA & \\
\hline & Sham-operated & Treated & Saline & Treated \\
\hline Dorsal hipp & & & & \\
\hline $5-\mathrm{HT}$ & $3.51 \pm 0.25$ & $0.21 \pm 0.13^{* * *}$ & $3.18 \pm 0.28$ & $0.20 \pm 0.07^{* * *}$ \\
\hline NA & $4.33 \pm 0.74$ & $3.11 \pm 0.46$ & $3.44 \pm 0.23$ & $1.46 \pm 0.12^{* * *}$ \\
\hline NAC & & & & \\
\hline $5-\mathrm{HT}$ & $3.86 \pm 0.39$ & $0.19 \pm 0.12^{* * *}$ & $3.69 \pm 0.25$ & $0.24 \pm 0.03^{* * *}$ \\
\hline DA & $88.39 \pm 10.26$ & $75.52 \pm 5.19$ & $80.71 \pm 6.09$ & $43.68 \pm 5.04^{* * *}$ \\
\hline NA & n.d. & n.d. & n.d. & n.d. \\
\hline Striatum & & & & \\
\hline 5-HT & $2.92 \pm 0.35$ & $0.08 \pm 0.06^{* * *}$ & $1.89 \pm 0.11$ & $0.09 \pm 0.03 * * *$ \\
\hline DA & $103.39 \pm 7.17$ & $92.33 \pm 6.33$ & $94.02 \pm 8.34$ & $76.56 \pm 4.39$ \\
\hline NA & n.d. & n.d. & n.d. & n.d. \\
\hline SN & & & & \\
\hline $5-\mathrm{HT}$ & $12.20 \pm 3.38$ & $0.61 \pm 0.06^{* * *}$ & $14.55 \pm 1.67$ & $0.87 \pm 0.25^{* * *}$ \\
\hline DA & $12.25 \pm 1.70$ & $12.28 \pm 1.44$ & $11.25 \pm 2.73$ & $14.06 \pm 1.81$ \\
\hline NA & $5.03 \pm 0.60$ & $5.31 \pm 0.36$ & $4.65 \pm 0.33$ & $6.13 \pm 0.64$ \\
\hline VTA & & & & \\
\hline 5-HT & $9.44 \pm 1.08$ & $0.27 \pm 0.12^{* * *}$ & $6.10 \pm 0.73$ & $1.02 \pm 0.12^{* * *}$ \\
\hline DA & $8.72 \pm 1.09$ & $9.15 \pm 2.30$ & $12.54 \pm 3.46$ & $14.64 \pm 2.28$ \\
\hline NA & $9.88 \pm 1.07$ & $8.34 \pm 0.56$ & $10.44 \pm 1.39$ & $9.7 \pm 0.74$ \\
\hline
\end{tabular}

Each value, expressed in $\mathrm{ng} / \mathrm{mg}$ proteins, represents the mean $\pm \mathrm{SEM}$ of five or six independent determinations Measurements were performed $21 \mathrm{~d}$ after intra-raphe 5,7-dihydroxytryptamine (5,7-DHT) or vehicle injection (shamoperated rats) and $24 \mathrm{hr}$ after the last intraperitoneal administration of para-chlorophenylalanine (pCPA) or saline. ${ }^{* * *} p<$ 0.001 versus control animals (two-tailed Student's $t$ test). NAC, Nucleus accumbens; SN, substantia nigra; VTA, ventral tegmental area; n.d., not determined.

Table 2. Effect of 5,7-DHT or pCPA treatment on absolute basal levels of DA, DOPAC, and 5-HIAA in dialysates from the NAC and the striatum

\begin{tabular}{|c|c|c|c|c|}
\hline & \multicolumn{2}{|l|}{ 5,7-DHT } & \multicolumn{2}{|l|}{$\mathrm{pCPA}$} \\
\hline & Sham-operated & Treated & Saline & Treated \\
\hline \multicolumn{5}{|l|}{ NAC } \\
\hline DA & $6.9 \pm 0.9$ & $8.1 \pm 1.4$ & $6.2 \pm 0.9$ & $2.9 \pm 0.3^{* * *}$ \\
\hline DOPAC & $2956 \pm 623$ & $2843 \pm 459$ & $2609 \pm 376$ & $1665 \pm 123^{*}$ \\
\hline 5-HIAA & $626 \pm 43$ & $29 \pm 3.1^{* * *}$ & $665 \pm 62$ & $101 \pm 16^{* * *}$ \\
\hline \multicolumn{5}{|l|}{ Striatum } \\
\hline DA & $15.6 \pm 3.5$ & $18.8 \pm 3.4$ & $14.3 \pm 2.4$ & $7.2 \pm 0.9^{*}$ \\
\hline DOPAC & $3274 \pm 716$ & $4519 \pm 590$ & $2764 \pm 491$ & $1622 \pm 174^{*}$ \\
\hline 5-HIAA & $957 \pm 109$ & $25 \pm 3.5^{* * *}$ & $827 \pm 68$ & $114 \pm 16^{* * *}$ \\
\hline
\end{tabular}

Each value, expressed in $\mathrm{pg} / 30 \mu \mathrm{l}$ dialysates, represents the mean \pm SEM of five or six independent determinations of DA, DOPAC, and 5-HIAA basal levels in dialysates collected from the nucleus accumbens (NAC) and the striatum before dorsal raphe nucleus (DRN) electrical stimulation. Experiments were performed 18-21 d after intra-DRN 5,7dihydroxytryptamine (5,7-DHT) or vehicle injection (sham-operated rats) and $24 \mathrm{hr}$ after the last intraperitoneal administration of para-chlorophenylalanine (pCPA) or saline. ${ }^{*} p<0.05$ and ${ }^{* * *} p<0.001$ versus control animals (two-tailed Student's $t$ test).

in the striatum $(-34$ and $-30 \% ; p<0.01)$ and the NAC $(-47$ and $-61 \% ; p<0.001$ ) of pCPA-treated animals (data not shown).

Table 2 reports the basal extracellular levels of DA, DOPAC, and 5-HIAA in the NAC and the striatum of 5,7-DHT- or pCPA-treated animals. As expected by the extent of the lesion, revealed by ex vivo measurement, 5-HIAA dialysate content was reduced dramatically in both brain regions of 5,7-DHT-treated (approximately $-95 \%$; $p<0.001$ ) or pCPA-treated (approximately $-85 \% ; p<0.001$ ) animals. Accumbal and striatal DA and DOPAC basal outflows were not affected significantly by 5,7DHT lesion, whereas a moderate but significant reduction in DA and DOPAC dialysate content was found in both the NAC
$(-50 \%, p<0.05$ and $-37 \%, p<0.05$ for DA and DOPAC, respectively) and the striatum $(-54 \%$ for $\mathrm{DA}, p<0.01$ and $-31 \%$ for DOPAC, $p<0.05)$ of pCPA-treated animals.

\section{Effect of DRN electrical stimulation on DA, DOPAC, and 5-HIAA extracellular levels in the NAC and the striatum of 5,7-DHT- or pCPA-treated animals}

The effect of $20 \mathrm{~Hz}$ DRN stimulation on DA and DOPAC dialysate levels in the NAC and the striatum of 5,7-DHT- and pCPA-treated rats is illustrated in Figures 3 and 4, respectively. Intra-raphe 5,7-DHT injection abolished either the excitatory or the inhibitory effect induced by DRN stimulation on accumbal 


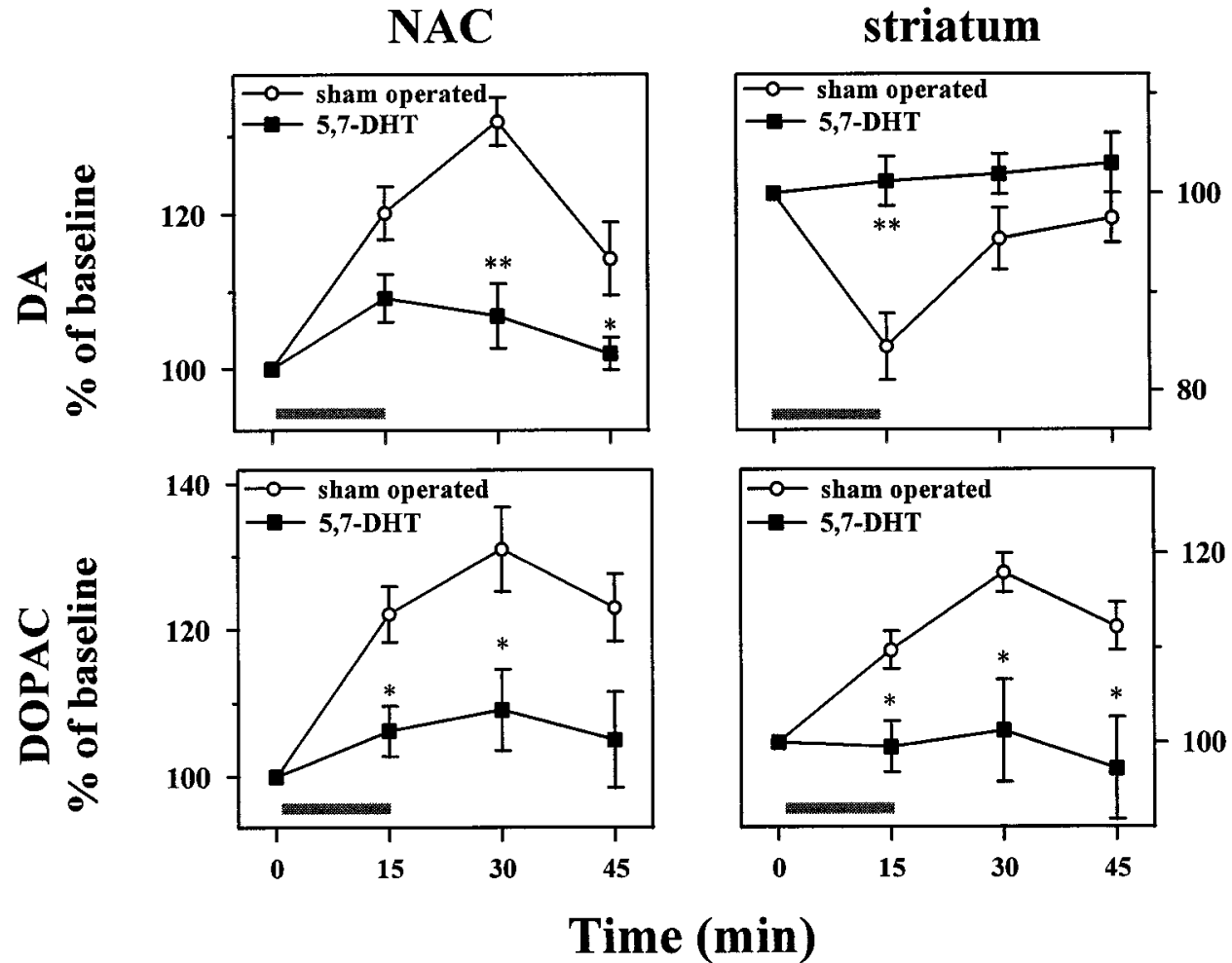

Figure 3. Time course of the effect of 20 $\mathrm{Hz}$ dorsal raphe nucleus (DRN) electrical stimulation on DA and DOPAC extracellular levels in the nucleus accumbens (NAC) and the striatum in sham-operated (unfilled circles) and 5,7-dihydroxytryptaminelesioned (5,7-DHT, filled squares) rats. Each data point represents the mean percentage \pm SEM of baseline values calculated from three samples before DRN stimulation, performed for a $15 \mathrm{~min}$ period as indicated by the horizontal bar. Each experiment was performed on five animals per group 18-21 d after intra-DRN injection of vehicle or 5,7-DHT. 5,7-DHT treatment reduced the overall effect of DRN stimulation on DA and DOPAC extracellular levels in both the NAC and the striatum (see Results). ${ }^{*} p<0.05$ and ${ }^{* *} p<0.01$ as compared with the sham-operated group for each time point (Student's $t$ test). and striatal DA release, respectively $\left[F_{(1,8)}=57.93, p<0.001\right.$ in the NAC and $F_{(1,8)}=9.15, p<0.05$ in the striatum]. In the NAC the reduction of DA dialysate content was maximal in fractions collected 15 min after the offset of stimulation $(p<0.01$, Student's $t$ test). The enhancement of DOPAC outflow induced by DRN stimulation was decreased significantly by 5,7-DHT lesioning in both the NAC $\left[F_{(1,8)}=7.39, p<0.05\right]$ and the striatum $\left[F_{(1,8)}=9.65, p<0.05\right]$.

As shown in Figure 4, pCPA treatment also prevented the effect of DRN stimulation on accumbal and striatal DA release $\left[F_{(1,10)}=23.28, p<0.001\right.$ for NAC; $F_{(1,10)}=5.78, p<0.05$ for striatum]. However, in contrast to 5,7-DHT, pCPA failed to modify significantly the enhancement of DOPAC outflow induced by DRN stimulation in both structures $\left[F_{(1,10)}=1.4\right.$ and 0.15 for the NAC and the striatum, respectively, not significant]. Finally, in 5,7-DHT-treated, but not in pCPA-treated, animals the accumbal and striatal 5-HIAA extracellular levels were no longer affected by DRN stimulation [in the 5,7-DHT experiment: $F_{(1,8)}=15.43, p<0.01$ and $F_{(1,8)}=6.82, p<0.05$ for the NAC and the striatum, respectively; in the pCPA experiment: $F_{(1,10)}=$ 2.3 , not significant and $F_{(1,10)}=1.2$, not significant for the NAC and the striatum (data not shown)].

\section{Effect of DRN electrical stimulation on DA, DOPAC, and 5-HIAA extracellular levels in the NAC and the striatum of $5-\mathrm{HT}_{3}$ antagonists-treated animals}

The involvement of $5-\mathrm{HT}_{3}$ receptors in the effects elicited by 20 $\mathrm{Hz}$ DRN stimulation was studied by using the selective $5-\mathrm{HT}_{3}$ receptor antagonists ondansetron and $(S)$-zacopride. As illustrated in Figure 5, the subcutaneous injection of 0.1 and $1 \mathrm{mg} / \mathrm{kg}$ ondansetron significantly reduced, to the same extent, the increase in accumbal DA release elicited by $20 \mathrm{~Hz}$ DRN stimulation $\left[F_{(1,17)}=6.45, p<0.05\right.$ and $F_{(1,17)}=13.6, p<0.01$ for 0.1 and 1 $\mathrm{mg} / \mathrm{kg}$ ondansetron, respectively]. A similar reduction also was observed after the subcutaneous administration of $0.1 \mathrm{mg} / \mathrm{kg}$ $(S)$-zacopride $\left[F_{(1,18)}=12.1, p<0.01\right.$; Fig. 6]. In all cases the blockade was maximal for dialysates collected 15 and 30 min after DRN stimulation ( $p<0.01$ and $p<0.001$, Tukey's test). In addition, DA dialysate levels in stimulated animals treated with $5-\mathrm{HT}_{3}$ antagonists were significantly different from those found in sham-stimulated animals given the $5-\mathrm{HT}_{3}$ antagonist $(p<0.05$, Tukey's test), indicating that $5-\mathrm{HT}_{3}$ antagonists did not antagonize completely the facilitatory effect induced by DRN stimulation on accumbal DA release. In contrast to the NAC, the decrease of DA release elicited by DRN stimulation in the striatum was affected neither by ondansetron $\left[F_{(1,17)}=1.7\right.$, not significant and $F_{(1,17)}=1.6$, not significant for 0.1 and $1 \mathrm{mg} / \mathrm{kg}$ ondansetron, respectively; Fig. 5] nor by $(S)$-zacopride $\left[F_{(1,18)}=0.02\right.$, not significant; Fig. 6].

The enhancement of extracellular DOPAC and 5-HIAA levels elicited by DRN stimulation in the NAC was modified significantly neither by ondansetron at both $0.1 \mathrm{mg} / \mathrm{kg}\left[F_{(1,17)}=0.42\right.$ and 0.78 , not significant for DOPAC and 5-HIAA, respectively $]$ and $1 \mathrm{mg} / \mathrm{kg}\left[F_{(1,17)}=3.67\right.$ and 2.43 , not significant for DOPAC and 5-HIAA, respectively $]$ nor by $(S)$-zacopride $\left[F_{(1,18)}\right.$ $=2.57$ and 0.63 , not significant for DOPAC and 5-HIAA, respectively] (data not shown). Also, in the striatum the 5- $\mathrm{HT}_{3}$ antagonists failed to modify the effect of DRN stimulation on both DOPAC and 5-HIAA dialysate levels [for DOPAC and 5-HIAA, respectively: $F_{(1,17)}=1.86$ and 1.3 , not significant for ondansetron $0.1 \mathrm{mg} / \mathrm{kg} ; F_{(1,17)}=2.88$ and 1.7 , not significant for ondansetron $1 \mathrm{mg} / \mathrm{kg} ; F_{(1,18)}=0.12$ and 2.12, not significant for $(S)$-zacopride $0.1 \mathrm{mg} / \mathrm{kg}$ ] (data not shown). Finally, none of the $5-\mathrm{HT}_{3}$ antagonists significantly modified, by themselves, either basal DA outflow (Figs. 5, 6; Tukey's test) or DOPAC and 5-HIAA extracellular levels (data not shown) in both brain regions. 


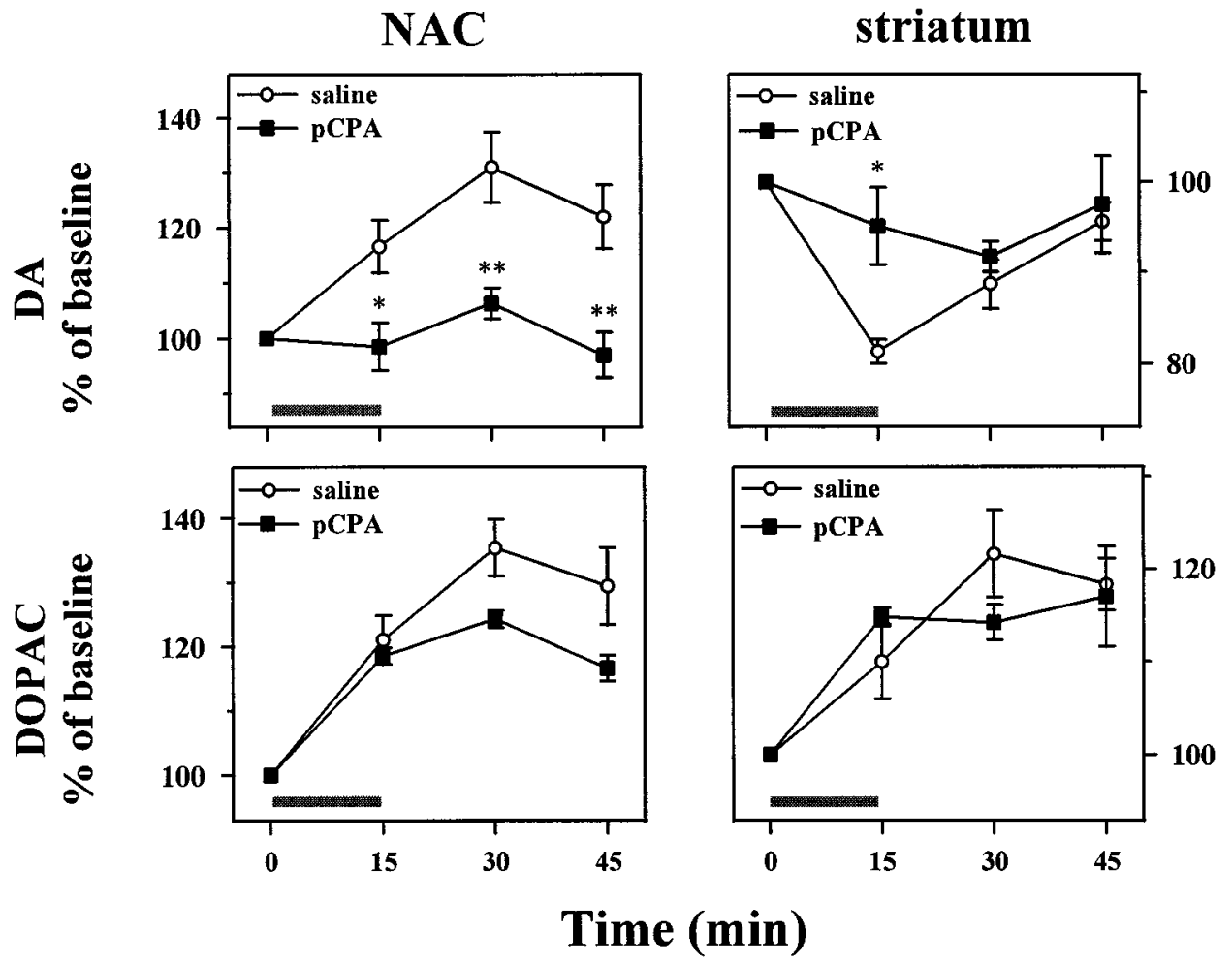

Figure 4. Time course of the effect of 20 $\mathrm{Hz}$ dorsal raphe nucleus (DRN) electrical stimulation on DA and DOPAC extracellular levels in the nucleus accumbens $(N A C)$ and the striatum in saline-treated (unfilled circles) and para-chlorophenylalaninetreated ( $p C P A$, filled squares) rats. Each data point represents the mean percentage \pm SEM of baseline values calculated from three samples before DRN electrical stimulation, performed for a $15 \mathrm{~min}$ period as indicated by the horizontal bar. Each experiment was performed on five or six animals per group $24 \mathrm{hr}$ after the last injection of saline or pCPA. In both the NAC and the striatum, pCPA treatment reduced the overall effect of DRN stimulation on DA, but not on DOPAC, extracellular levels (see Results). ${ }^{*} p<0.05$ and ${ }^{* *} p<0.01$ as compared with the saline group for each time point (Student's $t$ test).

\section{DISCUSSION}

This study shows that an enhancement of central 5-HT transmission induced by DRN stimulation elicits simultaneous and opposite changes of DA release in the NAC and striatum. Furthermore, $5-\mathrm{HT}_{3}$ receptors are involved selectively in the facilitatory control exerted by endogenous 5-HT on mesoaccumbal DA transmission.

As previously reported (De Simoni et al., 1985; Sharp et al., 1989), we found that 10 and $20 \mathrm{~Hz}$, but not 3 and $5 \mathrm{~Hz}, \mathrm{DRN}$ stimulation elicits a long-lasting increase of accumbal and striatal 5-HIAA extracellular levels. This indicates, although indirectly, that central 5-HT transmission is activated under our experimental conditions. Indeed, similar changes in 5-HIAA outflow, considered as an accurate index of 5-HT neuronal activity changes induced by DRN stimulation (Shannon et al., 1986; De Simoni et al., 1987), have been shown to be associated with a frequencydependent increase of 5-HT release (Sharp et al., 1989).

DRN stimulation at 5-20 Hz elicited a frequency-dependent enhancement of extracellular levels of accumbal DA and DOPAC. These results are in agreement with a previous report that an enhancement of DRN neuron activity, induced by intraDRN injection of glutamate, increases DA release in the NAC (Yoshimoto and McBride, 1992). To assess the involvement of endogenous 5-HT in the observed effects on DA neuron activity, we performed $20 \mathrm{~Hz}$ DRN stimulation in animals given either 5,7-DHT or pCPA. These two treatments, as previously reported (Koe and Weissman, 1966; Baumgarten et al., 1973; Kirby et al., 1995), dramatically reduced 5-HT tissue content (94-97\% and 83-96\%, respectively) as well as extracellular 5-HIAA levels (95-97\% and 85-86\%, respectively) throughout the brain. 5,7DHT and pCPA completely prevented the DRN stimulationinduced changes of accumbal DA release, thus providing strong evidence for the involvement of endogenous 5-HT in the effect of DRN stimulation. However, in contrast to 5,7-DHT, pCPA failed to prevent the effect of DRN stimulation on DOPAC outflow. Also, the magnitude of 5-HIAA outflow enhancement induced by DRN stimulation was not reduced significantly by pCPA. A lower efficacy of pCPA with respect to 5,7-DHT to impair central 5-HT transmission in DRN-stimulated rats may account for these findings. Indeed, given that 5-HT cell bodies are destroyed almost completely by 5,7-DHT (Compan et al., 1996), it is conceivable that the remaining efficacy of DRN stimulation to release cerebral 5-HT in 5-HT-depleted rats (McQuade and Sharp, 1995) should be greater in pCPA- than in 5,7-DHT-treated animals. Nevertheless, the extent to which pCPA treatment may modify DA neuron responsiveness to 5-HT because of its own effects on DA system activity (Koe and Weissman, 1966; Minabe et al., 1996; present study) cannot be ruled out.

The selective $5-\mathrm{HT}_{3}$ antagonists ondansetron and $(S)$ zacopride (Van Wijngaarden et al., 1990; Hoyer et al., 1994), without affecting basal DA outflow (Carboni et al., 1989b; Pei et al., 1993), significantly counteracted the effect of DRN stimulation on accumbal DA release. These results are consistent with several biochemical and behavioral studies showing that $5-\mathrm{HT}_{3}$ receptors are involved in the control of mesoaccumbal DA pathway activity. Thus, the facilitatory effect of $5-\mathrm{HT}_{3}$ agonists or exogenous 5-HT on accumbal DA release was reduced partially by $5-\mathrm{HT}_{3}$ antagonists (Jiang et al., 1990; Chen et al., 1991; Parsons and Justice, 1993). Also, 5- $\mathrm{HT}_{3}$ antagonists have been shown to counteract the increase of accumbal DA release induced by various drugs of abuse such as ethanol, nicotine, morphine, or cocaine (Carboni et al., 1989b; McNeish et al., 1993; Pei et al., 1993). Furthermore, behaviors related to drugs of abuse, resulting from the stimulation of the mesolimbic DA system, are reduced by $5-\mathrm{HT}_{3}$ antagonists (Costall et al., 1987; Hagan et al., 1987; Carboni et al., 1989a; Reith, 1990; Svingos and Hitzemann, 1992). However, in the case of amphetamine or cocaine, no effect of $5-\mathrm{HT}_{3}$ antagonists has been reported in some studies (Carboni et 


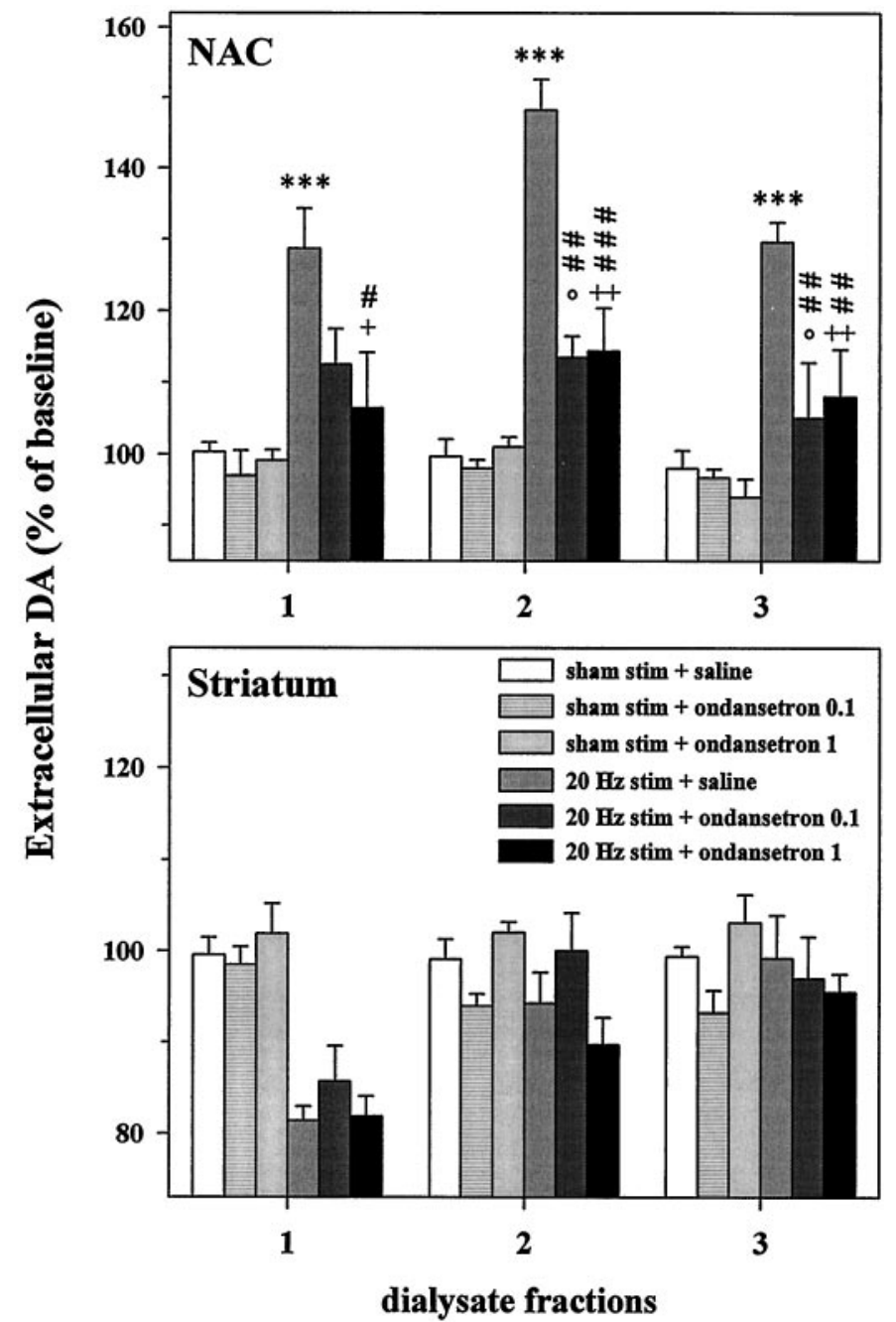

Figure 5. Time course of the effect of $20 \mathrm{~Hz}$ dorsal raphe nucleus (DRN) electrical stimulation on DA extracellular levels in the nucleus accumbens $(N A C)$ and the striatum in saline- and ondansetron-treated rats. Each column represents the mean percentage \pm SEM of the results from four to six animals per group of the three dialysate fractions collected during and after DRN stimulation, performed during the first dialysate fraction (15 min). Ondansetron, subcutaneously injected at $0.1 \mathrm{or} 1 \mathrm{mg} / \mathrm{kg} 30 \mathrm{~min}$ before DRN stimulation, significantly reduced the overall effect of DRN stimulation on DA release only in the NAC $(p<0.05$ and $p<0.01$, respectively, two-way ANOVA; see Results). ${ }^{* * *} p<0.001$ versus the sham stim + saline group; ${ }^{\#} p<0.05,{ }^{\# \#} p<0.01$, and ${ }^{\# \# \#} p<0.001$ versus the $20 \mathrm{~Hz}$ stim + saline group; ${ }^{\circ} p<0.05$ versus the sham stim + ondansetron 0.1 group; ${ }^{+} p<0.05$ and ${ }^{++} p<0.01$ versus the sham stim + ondansetron 1 group (Tukey's test for each time point).

al., 1989a,b; Cervo et al., 1996). It has been proposed that the enhancement of the VTA-DA neuron firing rate may be a crucial factor for the expression of $5-\mathrm{HT}_{3}$ receptor-mediated control of mesoaccumbal DA pathway activity (Carboni et al., 1989a,b; Jiang et al., 1990; Cervo et al., 1996). Nevertheless, considering that VTA-DA neuronal activity is frequency-dependently (up to $10 \mathrm{~Hz}$ ) reduced by DRN stimulation (Kelland et al., 1993), it is likely that the efficacy of ondansetron and $(S)$-zacopride to decrease DRN stimulation-induced accumbal DA release occurs independently of VTA-DA changes in neuronal firing rate. In line with this, $5-\mathrm{HT}_{3}$ antagonists are not able to inhibit a morphine-induced increase in the VTA-DA cell firing rate (Gifford and Wang, 1994) but do reduce its stimulatory effect on

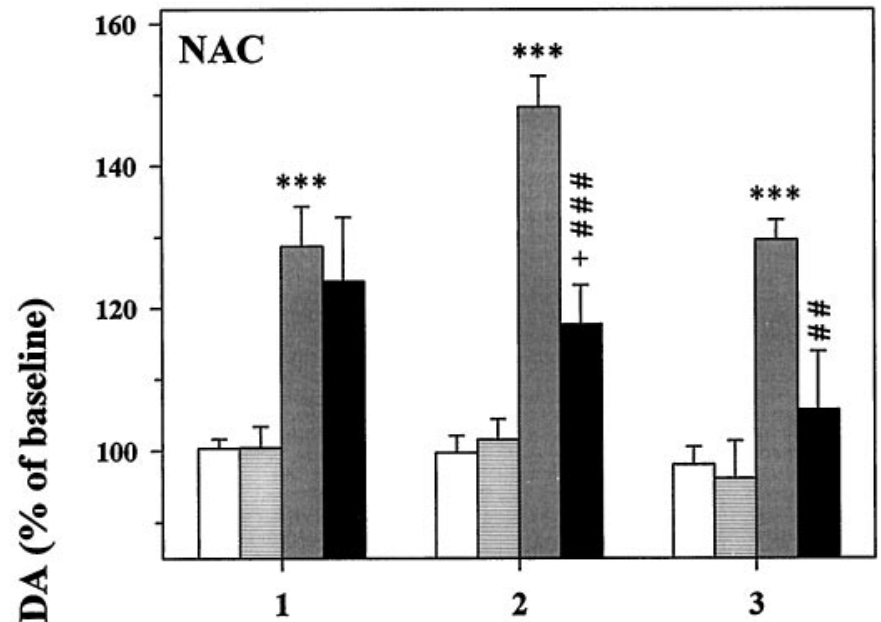

曷

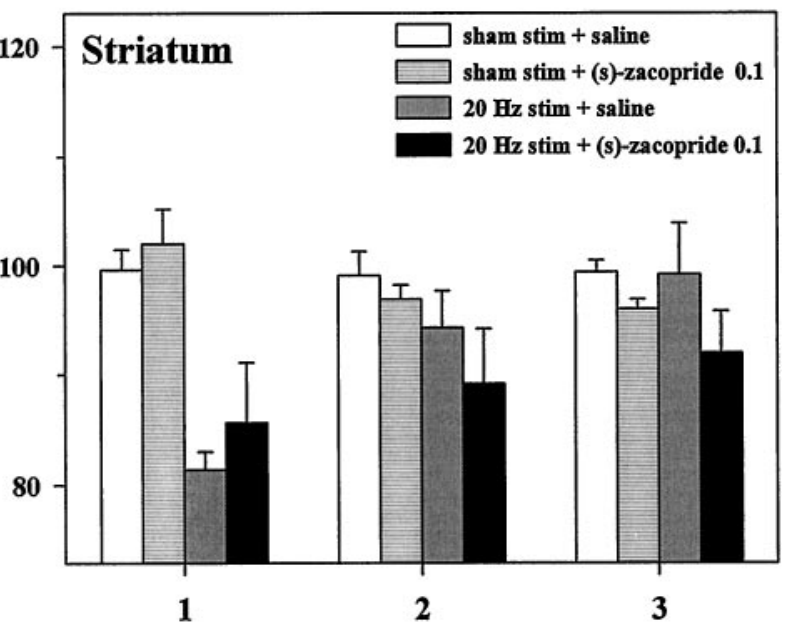

Dialysate fractions

Figure 6. Time course of the effect of $20 \mathrm{~Hz}$ dorsal raphe nucleus (DRN) electrical stimulation on DA and DOPAC extracellular levels in the nucleus accumbens $(N A C)$ and the striatum in saline- and $(S)$-zacopridetreated rats. Each column represents the mean percentage \pm SEM of the results from four to six animals per group of the three dialysate fractions collected during and after DRN stimulation, performed during the first dialysate fraction $(15 \mathrm{~min})$. ( $S$ )-zacopride, subcutaneously injected at 0.1 $\mathrm{mg} / \mathrm{kg} 30 \mathrm{~min}$ before DRN stimulation, significantly reduced the overall effect of DRN stimulation on DA release only in the NAC $(p<0.01$, two-way ANOVA; see Results). ${ }^{* *} p<0.001$ versus the sham stim + saline group; ${ }^{\# \# p}<0.01$ and ${ }^{\# \# \#} p<0.001$ versus the $20 \mathrm{~Hz}$ stim + saline group; ${ }^{+} p<0.05$ versus the sham stim $+(\mathrm{S})$-zacopride 0.1 group (Tukey's test for each time point).

accumbal DA release (Imperato and Angelucci, 1989; Pei et al., 1993). 5- $\mathrm{HT}_{3}$ antagonists also fail to modify the increase of VTA-DA neuronal firing induced by 5-HT applied onto DA cell bodies (Pessia et al., 1994). Thus, our results, together with the above-mentioned data, suggest that factors other than the VTA-DA neuron impulse flow play a permissive role for the $5-\mathrm{HT}_{3}$ receptor-mediated control of accumbal DA release.

Given that $5-\mathrm{HT}_{3}$ receptors are located mainly downstream from monoaminergic pathways (Kidd et al., 1993; Morales and Bloom, 1997) and that DRN stimulation modifies neuronal activity throughout the brain (Andersen et al., 1983; Cudennec et al., 1988), the increase in accumbal DA release mediated by $5-\mathrm{HT}_{3}$ receptors probably involves a transsynaptic effect influencing the release of DA at the terminals. An effect of 5-HT within both the 
VTA and the NAC may contribute to the observed increase of accumbal DA release. Although the presence of $5-\mathrm{HT}_{3}$ receptors in the ventral midbrain is controversial (Perry, 1990; Laporte et al., 1993), intra-VTA injection of 5-HT and 5- $\mathrm{HT}_{3}$ agonists enhance, respectively, accumbal DA release (Guan and McBride, 1989) and locomotor activity (Mylecharane, 1996). This latter effect is blocked by the intra-VTA administration of ondansetron (Mylecharane, 1996). Also, microinjection of 5- $\mathrm{HT}_{3}$ antagonist into the VTA, but not into the NAC, reduces the morphineinduced increase of accumbal DA release (Imperato and Angelucci, 1989). On the other hand, as previously discussed, accumbal DA release also is enhanced after intra-NAC administration of 5-HT and 5- $\mathrm{HT}_{3}$ agonists (Chen et al., 1991; Parsons and Justice, 1993).

The finding that DRN stimulation-induced increase of accumbal DA release is not blocked completely by $5-\mathrm{HT}_{3}$ antagonists but is abolished by 5,7-DHT and pCPA treatments is compatible with the possibility that other 5-HT receptor subtypes also participate in the control of accumbal DA release (Guan and McBride, 1989; Parsons and Justice, 1993). In addition, the failure of $5-\mathrm{HT}_{3}$ antagonists to modify DOPAC outflow in the NAC is in accordance with previous studies showing that DA release and metabolism are controlled by different mechanisms (De Simoni et al., 1987), which probably are related to different 5-HT receptor subtypes.

In the striatum the DRN stimulation elicited a transient reduction of DA release at $20 \mathrm{~Hz}$ only, and a long-lasting and frequency-dependent enhancement of DOPAC extracellular levels. These results are consistent with previous data showing that, in the striatum, $10 \mathrm{~Hz}$ DRN stimulation enhances extracellular and tissular levels of DOPAC (De Simoni et al., 1985, 1987; Cudennec et al., 1988) but does not alter the tissular content of 3-methoxytyramine, an index of DA release (De Simoni et al., 1987).

The finding that 5,7-DHT and pCPA abolished the decrease of DA release induced by DRN stimulation strongly indicates the involvement of endogenous 5-HT in this effect. As for the NAC, pCPA failed to modify DRN stimulation-induced enhancement of striatal DOPAC extracellular levels. Consistent with the possibility that pCPA is less effective than 5,7-DHT to impair central 5-HT transmission in DRN-stimulated rats, DRN stimulationinduced increase of striatal DOPAC levels is suppressed by the 5-HT antagonist metergoline (De Simoni et al., 1985).

In contrast to the NAC, 5- $\mathrm{HT}_{3}$ antagonists failed to modify either basal or DRN stimulation-induced changes of striatal DA release and metabolism. This finding agrees with all available biochemical studies (Zazpe et al., 1994; Bonhomme et al., 1995; Santiago et al., 1995) reporting that $5-\mathrm{HT}_{3}$ receptors are not involved in the control of striatal DA release, except for one (Blandina et al., 1989). Also, behaviors related to nigrostriatal DA pathway activity have been shown to be insensitive to $5-\mathrm{HT}_{3}$ receptor antagonists (Costall et al., 1987; Hicks, 1990).

In regard to the effect of 5-HT on the nigrostriatal DA pathway, several studies indicate that $5-\mathrm{HT}$, via its action within the SN, exerts an inhibitory effect on nigrostriatal DA pathway activity (James and Starr, 1980; Kelland et al., 1990). However, an enhancement of striatal DA release has been reported after intrastriatal application of 5-HT (Benloucif and Galloway, 1991; Bonhomme et al., 1995). It is tempting to speculate that the DRN stimulation-induced decrease of striatal DA release may reflect a predominance of 5-HT action in the SN over its action in the striatum (Cudennec et al., 1988).
Our results, together, show that endogenous 5-HT exerts opposite effects on accumbal and striatal DA release and strongly support the hypothesis that $5-\mathrm{HT}_{3}$ receptors selectively modulate accumbal DA release. This is consistent with anatomical studies reporting that high-density $5-\mathrm{HT}_{3}$ receptors are found in limbic areas with respect to the nigrostriatal system (Kilpatrick et al., 1987; Barnes et al., 1990). Also, it recently has been shown that the simultaneous increase of accumbal and striatal DA release induced by the administration of the sigma agonist $(+) \mathrm{SKF}$ 10047 was reduced by $5-\mathrm{HT}_{3}$ antagonists in the NAC only (Volonté et al., 1995).

In conclusion, an enhancement of central 5-HT transmission differentially affects striatal and accumbal DA release, and endogenous 5-HT, via 5- $\mathrm{HT}_{3}$ receptors, exerts a facilitatory control restricted to the mesoaccumbal DA pathway. These results provide experimental support for recent clinical studies proposing the therapeutic use of $5-\mathrm{HT}_{3}$ antagonists to reduce selectively the mesolimbic DA hyperactivity, without altering the function of the nigrostriatal DA system. Indeed, it has been reported that ondansetron improves levodopa-induced psychosis in Parkinsonian patients without inducing motor deterioration or suppression of antiparkinsonian action of levodopa (Zoldan et al., 1995). Although the ability of atypical neuroleptics to block central $5-\mathrm{HT}_{3}$ receptors may contribute to their therapeutic advantage (Meltzer and Nash, 1991; Ashby and Wang, 1996), the clinical benefit of $5-\mathrm{HT}_{3}$ antagonists in the treatment of schizophrenia remains to be established (Greenshaw, 1993; Tricklebank, 1996). Additional studies are required to ascertain their role in the pathophysiology of neuropsychiatric disorders related to the overactivity of the mesolimbic DA system.

\section{REFERENCES}

Andersen E, Rigor B, Dafny N (1983) Electrophysiological evidence of concurrent dorsal raphe input to caudate, septum, habenula, thalamus, hippocampus, cerebellum, and olfactory bulb. Int J Neurosci 18:107-116.

Ashby Jr CR, Wang RY (1996) Pharmacological actions of the typical antipsychotic drug clozapine: a review. Synapse 24:349-394.

Azmitia EC, Segal M (1978) An autoradiographic study of the differential ascending projections of the dorsal and median raphe nuclei in the rat. J Comp Neurol 179:641-668.

Barnes JM, Barnes NM, Champaneria S, Costall B, Naylor RJ (1990) Characterisation and autoradiographic localisation of $5-\mathrm{HT}_{3}$ receptor recognition sites identified with $\left[{ }^{3} \mathrm{H}\right]-(S)$-zacopride in the forebrain of the rat. Neuropharmacology 29:1037-1045.

Baumgarten HC, Bjorklund A, Lackenmayer L, Nobin A (1973) Evaluation of the effects of 5,7-dihydroxytryptamine on serotonin and catecholamine neurones in the rat CNS. Acta Physiol Scand 391:1-19.

Benloucif S, Galloway MP (1991) Facilitation of dopamine release in vivo by serotonin agonists: studies with microdialysis. Eur J Pharmacol 200:1-8.

Blandina P, Goldfarb J, Craddock-Royal B, Green JP (1989) Release of endogenous dopamine by stimulation of 5-hydroxytryptamine receptors in rat striatum. J Pharmacol Exp Ther 251:803-809.

Bonhomme N, De Deurwaerdère P, Le Moal M, Spampinato U (1995) Evidence for $5-\mathrm{HT}_{4}$ receptor subtype involvement in the enhancement of striatal dopamine release induced by serotonin: a microdialysis study in the halothane-anesthetized rats. Neuropharmacology 34:269-279.

Carboni E, Acquas E, Leone P, Di Chiara G (1989a) 5- $\mathrm{HT}_{3}$ receptor antagonists block morphine- and nicotine- but not amphetamineinduced reward. Psychopharmacology 97:175-178.

Carboni E, Acquas E, Frau R, Di Chiara G (1989b) Differential inhibitory effects of a $5-\mathrm{HT}_{3}$ antagonist on drug-induced stimulation of dopamine release. Eur J Pharmacol 164:515-519.

Cervo L, Pozzi L, Samanin R (1996) 5-HT 3 receptor antagonists do not modify cocaine place conditioning or the rise in extracellular dopamine in the nucleus accumbens. Pharmacol Biochem Behav 55:33-37. 
Chen J, Van Praag HM, Gardner EL (1991) Activation of 5-HT 3 receptor by 1-phenylbiguanide increases dopamine release in the rat nucleus accumbens. Brain Res 543:354-357.

Compan V, Dusticier N, Nioullon A, Daszuta A (1996) Opposite changes on striatal neuropeptide $\mathrm{Y}$ after immunoreactivity after partial and complete serotonergic depletion in the rat. Synapse 24:87-96.

Costall B, Domeney AM, Naylor RJ, Tyers MB (1987) Effects of the $5-\mathrm{HT}_{3}$ receptor antagonist, GR38032F, on raised dopaminergic activity system of the rat and marmoset brain. Br J Pharmacol 92:881-894.

Cudennec A, Duverger D, Serrano A, Scatton B, McKenzie ET (1988) Influence of ascending serotonergic pathways on glucose use in the conscious rat brain. II. Effects of electrical stimulation of the rostral raphe nuclei. Brain Res 444:227-246.

De Deurwaerdère P, Bonhomme N, Le Moal M, Spampinato U (1995) D-Fenfluramine increases striatal extracellular dopamine in vivo independently of serotonergic terminals or dopamine uptake sites. J Neurochem 65:1100-1108.

De Simoni M, Giglio R, Dal Toso G, Kostowski W, Algeri S (1985) Interaction between serotonergic and dopaminergic systems detected in striatum by differential pulse voltammetry. Eur J Pharmacol 111:289-290

De Simoni MG, Dal Toso G, Froditto F, Sokola A, Algeri S (1987) Modulation of striatal metabolism by the activity of dorsal raphe serotonergic afferences. Brain Res 411:81-88.

Deutch AY, Moghaddam B, Innis RB, Krystal JH, Aghajanian GK, Bunney BS, Charney DS (1991) Mechanisms of action of atypical antipsychotic drugs. Implication for novel therapeutic strategies for schizophrenia. Schizophr Res 4:121-156.

Fontana DJ, Daniels SE, Eglen RM, Wong EHF (1996) Stereoselective effects of $(R)$ - and $(S)$-zacopride on cognitive performance in a spatial navigation task in rats. Neuropharmacology 35:321-327.

Gifford AN, Wang RY (1994) The effect of 5-HT 3 receptor antagonists on the morphine-induced excitation of A10 dopamine cells: electrophysiological studies. Brain Res 638:325-328.

Greenshaw AJ (1993) Behavioural pharmacology of 5- $\mathrm{HT}_{3}$ receptor antagonists: a critical update on therapeutic potential. Trends Pharmacol Sci 14:265-270.

Guan XM, McBride WJ (1989) Serotonin microinfusion into the ventral tegmental area increases accumbens dopamine release. Brain Res Bull 23:541-547.

Hagan RM, Butler A, Hill JM, Jordan CC, Ireland SJ, Tyers MB (1987) Effect of the 5- $\mathrm{HT}_{3}$ receptor antagonist, GR38032F, on responses to injection of a neurokinin agonist into the tegmental area of the rat brain. Eur J Pharmacol 138:303-305.

Hicks PB (1990) The effect of serotoninergic agents on haloperidolinduced catalepsy. Life Sci 47:1609-1615.

Hoyer D, Clarke DE, Fozard JR, Hartig PR, Martin GR, Mylecharane EJ, Saxena PR, Humphrey PPA (1994) VII. International Union of Pharmacology classification of receptors for 5-hydroxytryptamine (serotonin). Pharmacol Rev 46:157-203.

Hui SCG, Sevilla EL, Ogle CW (1993) 5-HT 3 antagonists reduce morphine self-administration in rats. Br J Pharmacol 110:1341-1346.

Imperato A, Angelucci L (1989) 5- $\mathrm{HT}_{3}$ receptors control dopamine release in the nucleus accumbens of freely moving rats. Neurosci Lett 101:214-217.

James TA, Starr MS (1980) Rotational behaviour elicited by 5-HT in the rat: evidence for an inhibitory role of 5-HT in the substantia nigra and corpus striatum. J Pharm Pharmacol 32:196-200.

Jiang LH, Ashby Jr CR, Kasser RJ, Wang RY (1990) The effect of intraventricular administration of the $5-\mathrm{HT}_{3}$ receptor agonist 2-methylserotonin on the release of dopamine in the nucleus accumbens: an in vivo chronocoulometric study. Brain Res 513:156-160.

Kapur S, Remington G (1996) Serotonin-dopamine interaction and its relevance to schizophrenia. Am J Psychiatry 153:466-476.

Kelland MD, Freeman AS, Chiodo LA (1990) Serotonergic afferent regulation of the basic physiology and pharmacological responsiveness of nigrostriatal dopamine neurons. J Pharmacol Exp Ther 253:803-811.

Kelland MD, Freeman AS, Rubin J, Chiodo LA (1993) Ascending afferent regulation of rat midbrain dopamine neurons. Brain Res Bull 31:539-546.

Kidd EJ, Laporte AM, Langlois X, Fattaccini CM, Doyen C, Lombard MC, Gozlan H, Hamon M (1993) 5- $\mathrm{HT}_{3}$ receptors in the rat central nervous system are mainly located on nerve fibers and terminals. Brain Res 612:289-298.

Kilpatrick GJ, Jones BJ, Tyers MB (1987) Identification and distribution of $5-\mathrm{HT}_{3}$ receptors in rat brain using radioligand binding. Nature 330:746-748

Kirby LG, Kreiss DS, Singh A, Lucki I (1995) Effect of destruction of serotonin neurons on basal and fenfluramine-induced serotonin release in striatum. Synapse 20:99-105.

Koe BK, Weissman A (1966) $p$-Chlorophenylalanine: a specific depletor of brain serotonin. J Pharmacol Exp Ther 154:499-516.

Laporte AM, Kidd EJ, Vergé D, Gozlan H, Hamon M (1993) Autoradiographic mapping of central $5-\mathrm{HT}_{3}$ receptors. In: Central and peripheral 5- $\mathrm{HT}_{3}$ receptors (Hamon $\mathrm{M}$, ed), pp 157-187. London: Academic.

Lowry OH, Rosebrough NJ, Farr AL, Randall RJ (1951) Protein measurement with the Folin phenol reagent. J Biol Chem 193:265-275.

McNeish CS, Svingos AL, Hitzemann R, Strecker RE (1993) The 5-HT antagonist $(S)$-zacopride attenuates cocaine-induced increases in extracellular dopamine in rat nucleus accumbens. Pharmacol Biochem Behav 45:759-763.

McQuade R, Sharp T (1995) Release of cerebral 5-hydroxytryptamine evoked by electrical stimulation of the dorsal and median raphe nuclei: effect of a neurotoxic amphetamine. Neuroscience 68:1079-1088.

Meltzer HY, Nash JF (1991) Effects of antipsychotic drugs on serotonin receptors. Pharmacol Rev 43:587-604.

Minabe Y, Emori K, Ashby Jr CR (1996) The depletion of brain serotonin levels by para-chlorophenylalanine administration significantly alters the activity of midbrain dopamine cells in rats: an extracellular single cell recording study. Synapse 22:46-53.

Morales M, Bloom FE (1997) The 5-HT 3 receptor is present in different subpopulations of GABAergic neurons in the rat telencephalon. J Neurosci 17:3157-3167.

Mylecharane EJ (1996) Ventral tegmental area 5-HT receptors: mesolimbic dopamine release and behavioural studies. Behav Brain Res 73:1-5.

Parsons LH, Justice JB (1993) Perfusate serotonin increases extracellular dopamine in the nucleus accumbens as measured by in vivo microdialysis. Brain Res 606:195-199.

Paxinos G, Watson C (1986) The rat brain in stereotaxic coordinates, 2nd Ed. New York: Academic.

Pei Q, Zetterström T, Leslie RA, Grahame-Smith DG (1993) 5- $\mathrm{HT}_{3}$ receptor antagonists inhibit morphine-induced stimulation of mesolimbic dopamine release and function in the rat. Eur $\mathrm{J}$ Pharmacol 230:63-68.

Pellegrino LJ, Cushman AJ (1967) A stereotaxic atlas of the rat brain. New York: Meredith.

Peltier R, Schenk S (1991) GR38032F, a serotonin 5-HT 3 antagonist, fails to alter cocaine self-administration in rats. Pharmacol Biochem Behav 39:133-136.

Perry DC (1990) Autoradiography of $\left[{ }^{3} \mathrm{H}\right]$ quipazine in rodent brain. Eur J Pharmacol 187:75-85.

Pessia M, Jiang ZG, North RA, Johnson SW (1994) Actions of 5-hydroxytryptamine on ventral tegmental area neurons of the rat in vitro. Brain Res 654:324-330.

Reith MEA (1990) 5- $\mathrm{HT}_{3}$ receptor antagonists attenuate cocaineinduced locomotion in mice. Eur J Pharmacol 186:327-330.

Santiago M, Machado A, Cano J (1995) 5- $\mathrm{HT}_{3}$ receptor agonist induced carrier-mediated release of dopamine in rat striatum in vivo. $\mathrm{Br} \mathrm{J}$ Pharmacol 116:1545-1550.

Shannon NJ, Gunnet JW, Moore KE (1986) A comparison of biochemical indices of 5-hydroxytryptaminergic neuronal activity following electrical stimulation of the dorsal raphe nucleus. J Neurochem 47:958-965.

Sharp T, Bramwell SR, Clark D, Grahame-Smith DG (1989) In vivo measurement of extracellular 5-hydroxytryptamine in hippocampus of the anaesthetized rat using microdialysis: changes in relation to 5hydroxytryptaminergic neuronal activity. J Neurochem 53:234-240.

Soubrié P, Reisine TD, Glowinski J (1984) Functional aspects of serotonin transmission in the basal ganglia: a review and in vivo approach using the push-pull cannula technique. Neuroscience 13:605-625.

Svingos AL, Hitzemann R (1992) 5- $\mathrm{HT}_{3}$ receptor antagonists block cocaine-induced locomotion via a PCPA-sensitive mechanism. Pharmacol Biochem Behav 43:871-879. 
Trent F, Tepper TM (1991) Dorsal raphe stimulation modifies striatalevoked antidromic invasion of nigral dopaminergic neurons in vivo. Exp Brain Res 84:620-630.

Tricklebank MD (1996) The antipsychotic potential of subtype-selective 5-HT receptor ligands based on interactions with mesolimbic dopamine systems. Behav Brain Res 73:11-13.

Van Bockstaele EJ, Cestari DM, Pickel VM (1994) Synaptic structure and connectivity of serotonin terminals in the ventral tegmental area: potential sites for modulation of mesolimbic dopamine neurons. Brain Res 647:307-322.

Van Wijngaarden J, Tulp M, Soudijn W (1990) The concept of selectivity in 5-HT receptor research. Eur J Pharmacol 188:301-312.

Volonté M, Ceci A, Borsini F (1995) Effect of the 5-hydroxytryptamine ${ }_{3}$ receptor antagonist itasetron (DAU 6215) on (+)- $N$-allylnormetazocine- induced dopamine release in the nucleus accumbens and in the corpus striatum of the rat: an in vivo microdialysis study. J PharmacolExp Ther 275:358-367.

Wirtshafter D, Stratford TR, Asin KE (1987) Evidence that serotonergic projections to the substantia nigra in the rat arise in the dorsal, but not the median, raphe nucleus. Neurosci Lett 77:261-266.

Yoshimoto K, McBride WJ (1992) Regulation of nucleus accumbens dopamine release by the dorsal raphe nucleus in the rat. Neurochem Res 17:401-407.

Zazpe A, Artaiz I, Del Rio J (1994) Role of 5-HT 3 receptors in basal $\mathrm{K}^{+}$-evoked dopamine release from rat olfactory tubercle and striatal slices. Br J Pharmacol 113:968-972.

Zoldan J, Friedberg G, Livneh M, Melamed E (1995) Psychosis in advanced Parkinson's disease: treatment with ondansetron, a 5- $\mathrm{HT}_{3}$ receptor antagonist. Neurology 45:1305-1308. 